\title{
Twenty-Four Months of Follow-up after Partial Removal of Carious Dentin: A Preliminary Study
}

\section{Rando-Meirelles MPM, Tôrres LHN and Sousa MLR*}

Department of Community Dental Health, Piracicaba Dental School, University of Campinas-UNICAMP, 13414-903, Piracicaba, SP, Brazil

\begin{abstract}
Aim: Minimal intervention seeks to prevent and detect oral diseases at the earliest stage in order to minimize invasive treatment. The aim of this study was to compare the clinical and radiographic outcomes of permanent molar teeth with deep lesions treated by
\end{abstract} complete or partial removal of carious dentin after follow-up over a 24-month period.

Methods: A total of 20 adolescents from Piracicaba, São Paulo, Brazil were screened; 11 had at least one deep carious lesion in permanent molars. Adolescents in whom 18 permanent molars required attention were randomly allocated to receive interventions. In the control group, nine teeth were submitted to complete removal of carious dentin, protection with calcium hydroxide and glass ionomer cement and restoration with resin composite. In the experimental group nine teeth were submitted to partial removal of carious dentin, protection with glass ionomer cement and restoration with resin composite. Radiographic examination and pulp vitality tests were performed 12-24 months after cavity sealing and the teeth were not reopened.

Results: Complete data were available for 16 teeth. One volunteer in the experimental group felt pain during the pulp vitality test after 12 months; however, there was spontaneous remission of symptoms and no image suggestive of periapical lesion. No teeth presented unsatisfactory clinical and radiographic response to treatment.

Conclusions: The results suggest that partial removal of carious dentin in a single session in permanent teeth could be indicated to maintain pulp vitality since no unsatisfactory clinical and radiographic results were shown.

Keywords: Dental caries; Molar; Dentin; Dental pulp test

Abbreviations: MID: Minimal Intervention Dentistry; PR: Experimental Group; TR: Control Group; MI: Marginal Integrity; VT: Vitality Tests; PT: Periapical Tissue; CL: Caries Lesion

\section{Introduction}

With the development of new adhesive materials and a more conservative approach, a new era of minimally invasive dentistry has dawned [1]. Also known as Minimal Intervention Dentistry (MID), in practice, it seeks to prevent and detect oral diseases at the earliest stage in order to minimize invasive treatment; and where clinical intervention is indicated, the least invasive restorative technique is used [2]. Thus, maintenance of pulpal vitality is the primary objective of conservative treatment of deep carious lesion [3] with partial caries removal being one of the possibilities of achieving this goal.

Dental caries is an infectious process caused by acids from bacterial metabolism diffusing into enamel and dentin and dissolving the mineral. There are many possibilities for intervening in this continuing process in order to arrest or reverse lesion progression [4] and one of these could be to modify the biofilm [5]. At an advanced stage of caries a cavitated carious lesion can retain the biofilm and careful brushing cannot remove it. Thus, the role of operative dentistry is to restore the integrity of the tooth so that the patient can clean effectively [6].

The treatment of deep carious lesions approaching the healthy pulp presents the practitioner with a significant challenge, and recent concepts in caries management have not yet been adopted in everyday practice $[7,8]$. Although partial caries removal would appear to be preferable to complete caries removal in deep lesions, in order to decrease the risk of pulp exposure $[6,7,9,10]$, in a recent network survey, only approximately $20 \%$ of dentists favored partial caries removal techniques in deep lesions [11]. Thompson et al. [7] suggested that before this concept can be accepted by the dental profession, additional clinical trials will be necessary.

In addition to decreasing the risk of pulp exposure, a more conservative approach could be a patient-friendly treatment to repair the reversible damage of the disease [12]. Furthermore, preventing the need for endodontic treatment, which could be the next step after pulp exposure, would reduce treatment time and cost. Therefore, in community health dentistry, more patients would be treated with the same financial resources.

In developing countries, where the financial resources for health are limited and the majority of the population depends on the Public Health Services, the difficulty of access to specialized treatment is considered a risk factor for tooth loss. Patients without alternative prefer tooth extraction to enduring the pain.

However, whilst there is evidence that partial caries removal can be the elective treatment, there is insufficient evidence to indicate whether it would be necessary to re-enter and excavate further in a stepwise excavation [9]. Considering that after sealing, the level of colonization in partial caries removal is similar to that in complete caries removal for all microorganisms [13-15] and carious lesions can be arrested if the restoration margins remain sealed [16,17], the aim of this study was to compare the clinical and radiographic outcomes of permanent molar teeth with deep lesions after partial caries removal in a single session, or complete caries removal and definitive restoration, during followup over a 24 -month period. The research hypothesis was that partial caries removal in a single session could be indicated for deep lesions in permanent molars in adolescents.

*Corresponding author: Professor Maria da Luz Rosário de Sousa, Department of Community Dental Health, Piracicaba Dental School, P.O. BOX 52, University of Campinas-UNICAMP, 13414-903, Piracicaba, SP, Brazil, Tel: 00551921065364 Fax: 005519 34210144; E-mail: luzsousa@fop.unicamp.br

Received September 13, 2013; Accepted October 09, 2013; Published October 11,2013

Citation: Rando-Meirelles MPM, Tôrres LHN, Sousa MLR (2013) Twenty-Four Months of Follow-up after Partial Removal of Carious Dentin: A Preliminary Study. Dentistry 3: 162. doi:10.4172/2161-1122.1000162

Copyright: (c) 2013 Rando-Meirelles MPM, et al. This is an open-access article distributed under the terms of the Creative Commons Attribution License, which permits unrestricted use, distribution, and reproduction in any medium, provided the original author and source are credited. 


\section{Material and Methods}

\section{Ethics}

This twenty-four month randomized controlled clinical preliminary study was conducted among adolescents residing in Piracicaba, São Paulo, Brazil. Approval was obtained from the Ethics Committee of the Piracicaba Dental School, University of Campinas (Report No. 102/2006) and written terms of free and informed consent to participate in the study were obtained from the adolescent's parents.

\section{Sample size}

The volunteers of this study took part in a previous study in which the prevalence of clinically undetected caries lesions was verified in Piracicaba, Brazil [18]. All adolescents that had at least one deep occlusal lesion in this previous study were invited to participate in the present study.

The following inclusion criteria were applied: adolescents from 12 to 17 years old, with at least one deep carious occlusal lesion in a permanent molar, presenting a radiographic radiolucent image with extension equal to or greater than the middle third of the dentin, however, without attaining the pulp chamber. Adolescents were not admitted to the study if any of the following exclusion criteria were present: proximal, bucco lingual or palate lingual lesions and radiographic images suggesting periapical lesion in the tooth under study; spontaneous pain or exaggerated sensitivity response to vitality tests; insufficient address or unwillingness to return for follow-up. Twenty volunteers were screened and 11 were found to meet the eligibility criteria (Figure 1). In order to diagnose the lesion and include the tooth in the study, periapical and interproximal (bitewing) radiographs were taken.

\section{Randomization}

Adolescents in whom the 18 teeth required treatment had an equal probability of being assigned to the two groups. The sample was randomized using a random-number table. They were distributed with regard to the type of treatment to be performed, which effectively meant a total of 9 teeth in the control group and 9 teeth in the experimental group (Figure 1). The adolescent who had more than one lesion requiring treatment had probability of being allocated to the 2 groups, for example, volunteers 1, 6, 7, 8 and 9 (Table 1).

\section{Restorative procedure}

All adolescents were instructed regarding oral hygiene procedures and received dental care at the Dentistry Clinic of Piracicaba Dental School where this study was conducted.

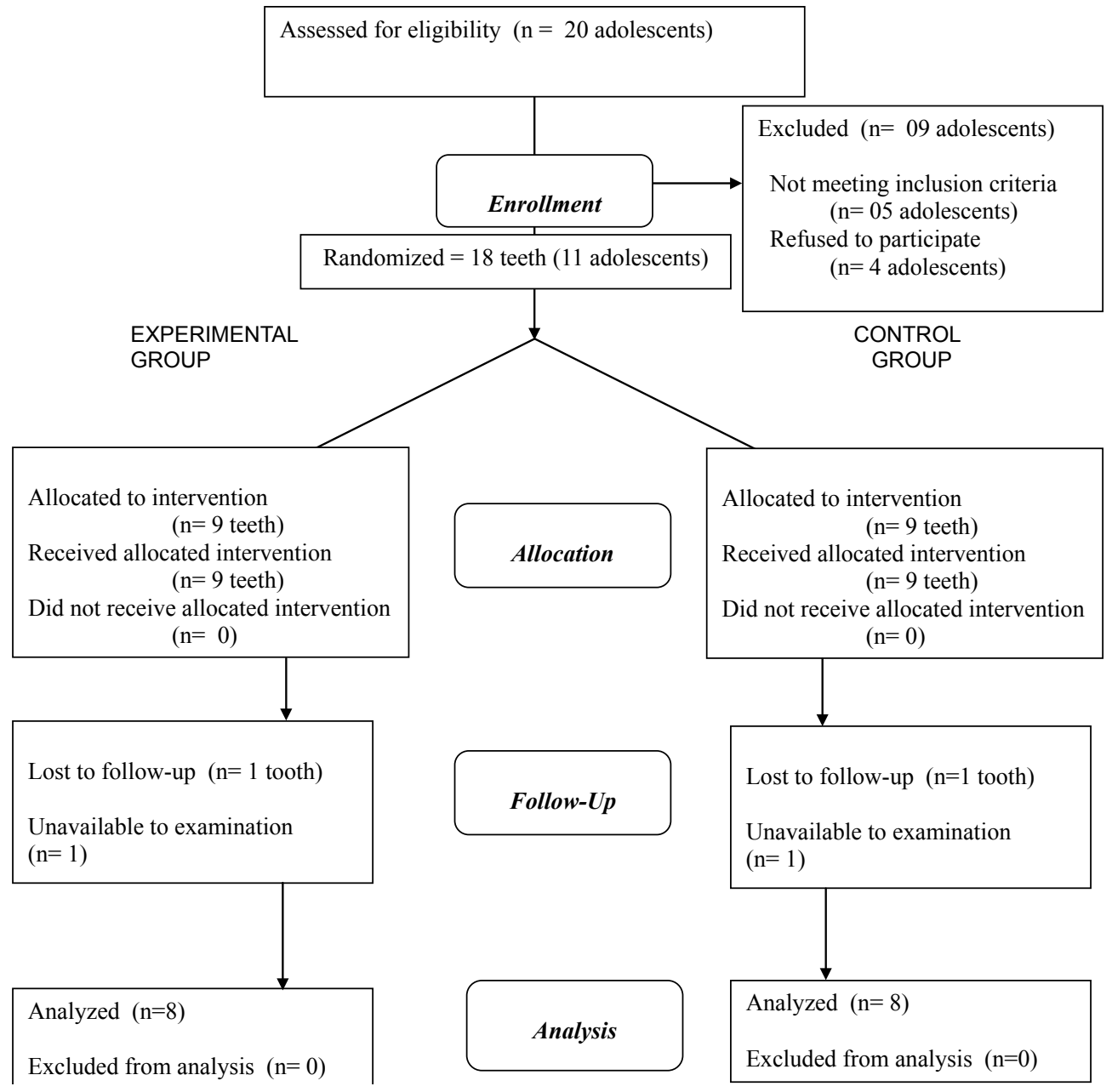

Figure 1: Flow diagram of the progress through the study phases according to the CONSORT statement (Moher et al., 2001). 
There was only one trained operator who was an expert in clinical treatment. In both groups the area to be treated was anesthetized and isolated with a rubber dam. Some of the teeth had no cavity; that is to say, the enamel was whole and in these cases, access to the lesion was performed with high speed burs.

In the control group, conventional treatment was performed, with complete removal of carious dentin (TR) using low speed burs and an excavator. The complete removal of carious dentin meant removal all of soft tissue until hard dentin was reached. For lining, calcium hydroxide cement (Dycal, Caulk/Dentsply, Rio de Janeiro, Brazil) and conventional glass ionomer cement (Vidrion F, S.S.White Brazil, Rio de Janeiro, Brazil) were used as base. For the definitive restoration, an adhesive system and resin composite (Single Bond and Filtek Z 350, $3 \mathrm{M}$, St. Paul, MN, USA) were used.

In the experimental group, the carious dentin was partially removed (PR) with an excavator for this purpose. The peripheral carious dentin; that is, the adjacent walls were completely removed; however, the

Table 1: Characteristics of the sample. Piracicaba, Brazil. 2007.

\begin{tabular}{|c|c|c|c|c|}
\hline Volunteer & Age & Gender & Tooth & Follow-Up (Month) \\
\hline 1 & 17 & $M$ & 17 & 24 \\
\hline 1 & 17 & $M$ & 27 & 24 \\
\hline 1 & 17 & $M$ & 37 & 24 \\
\hline 2 & 15 & $\mathrm{~F}$ & 47 & 18 \\
\hline 3 & 12 & M & 16 & 18 \\
\hline 4 & 15 & $M$ & 46 & $x$ \\
\hline 5 & 15 & M & 36 & $x$ \\
\hline 6 & 12 & $M$ & 17 & 18 \\
\hline 6 & 12 & $M$ & 26 & 18 \\
\hline 7 & 13 & $\mathrm{~F}$ & 46 & 24 \\
\hline 7 & 13 & $\mathrm{~F}$ & 47 & 24 \\
\hline 7 & 13 & $\mathrm{~F}$ & 37 & 18 \\
\hline 8 & 12 & $\mathrm{~F}$ & 27 & 24 \\
\hline 8 & 12 & $\mathrm{~F}$ & 16 & 24 \\
\hline 9 & 12 & $\mathrm{~F}$ & 36 & 18 \\
\hline 9 & 12 & $\mathrm{~F}$ & 46 & 18 \\
\hline 10 & 12 & M & 26 & 12 \\
\hline 11 & 12 & $\mathrm{~F}$ & 16 & 12 \\
\hline
\end{tabular}

carious dentin on the pulp wall was not removed. Conventional glass ionomer cement (Vidrion F, S.S. White Brazil, Rio de Janeiro, Brazil) was used for lining, and the definite restoration was performed with an adhesive system and resin composite (Single Bond and Filtek Z 350, $3 \mathrm{M}$, St Paul, MN, USA).

\section{Radiographic follow-up and pulp vitality test}

Radiographic follow-up was performed every six months over a period of 24 months, and periapical and interproximal radiographs were taken. Pulp vitality tests were performed with refrigerated gas (Aerojet, Rio de Janeiro, Brazil). These tests were performed in the first step before the restorative procedure, and at all the stages of radiographic follow-up.

\section{Criteria for clinical and radiographic evaluation}

The two types of treatment being studied were evaluated clinically according to marginal integrity (MI) and vitality tests (VT); radiographically according to eventual changes in periapical tissue (PT) and caries lesion (CL). The criteria ranged from the best to the worst rating. The result was considered good, satisfactory or unsatisfactory, if at least one of the criteria described in Table 2 were present.

\section{Statistical analyses}

The Mann Whitney test was applied to compare the mean followup time between the two groups, using the Microsoft Office Excel 2003-2007software program.

\section{Results}

The characteristics of the sample are shown in detail in Table 1. The final sample consisted of 16 teeth in 9 patients, as two volunteers withdrew from the research, one being from the control and the other from the experimental group. The mean age of the participants was 15.8 years and the teeth most commonly assessed were 16 and 46 (first molars).

Table 3 demonstrates the number of teeth followed-up in each group, and the success rate after radiographic and clinical examinations. There was no treatment considered unsatisfactory. Only one patient reported exaggerated response during the thermal test, however, with total remission of symptoms immediately after removal of the stimulus.

Table 2: Criteria for clinical and radiographic evaluation.

\begin{tabular}{|c|c|c|c|c|}
\hline & \multicolumn{4}{|l|}{ Criteria } \\
\hline & \multicolumn{2}{|l|}{ Clinical } & \multicolumn{2}{|l|}{ Radiographic } \\
\hline & Marginal Integrity & Vitalily Tests & Periapical Tissue & Caries Lesion \\
\hline Good & Without failure & No sensitivity & No image suggesting periapical lesion & Apparent arrest of the carious process \\
\hline Satisfactory & Partial failure & $\begin{array}{l}\text { Sensitivity during test with total } \\
\text { remission of the symptoms }\end{array}$ & No image suggesting periapical lesion & Apparent arrest of the carious process \\
\hline Unsatisfactory & Total failure & Spontaneous sensitivity & Image suggesting periapical lesion & Increase of the lesion \\
\hline
\end{tabular}

Table 3: Rate of success after radiographic examination (RE) and pulp vitality test (VT) in the experimental group (PR) and control group (TR)

\begin{tabular}{|c|c|c|c|c|c|c|c|c|}
\hline & \multicolumn{8}{|c|}{ Treament group and test } \\
\hline & \multicolumn{4}{|c|}{ PR } & \multicolumn{4}{|c|}{ TR } \\
\hline & \multicolumn{2}{|c|}{ RE } & \multicolumn{2}{|c|}{ VT } & \multicolumn{2}{|c|}{ RE } & \multicolumn{2}{|c|}{ VT } \\
\hline & $\mathrm{N}$ & $\%$ & $\mathrm{n}$ & $\%$ & $\mathrm{n}$ & $\%$ & $\mathrm{~N}$ & $\%$ \\
\hline Good & 8 & 100 & 7 & 87.5 & 8 & 100 & 8 & 100 \\
\hline Satisfactory & 0 & 0 & 1 & 12.5 & 0 & 0 & 0 & 0 \\
\hline Unsatisfactory & 0 & 0 & 0 & 0 & 0 & 0 & 0 & 0 \\
\hline TOTAL & 8 & 100 & 8 & 100 & 8 & 100 & 8 & 100 \\
\hline
\end{tabular}


This tooth (26) was part of the experimental group and it was rated as satisfactory response to vitality test. Apart from this case, all other teeth treatment were evaluated as good.

In the control group (TR) the mean follow-up time was 21 $(\mathrm{SD}=3.21)$ months and in the experimental group (PR) it was 18.7 $(\mathrm{SD}=5.01)$ months. This difference was not statistically significant $(\mathrm{p}=0.36)$, data not shown.

\section{Discussion}

The findings of this study show positive clinical and radiographic outcomes after partial caries removal in a single session, suggesting that there is no need for a complete caries removal since this could expose the pulp, and it is possible to perform the procedure in a single session. The partial removal of carious dentin has been documented [6,1923], and indicated as one step of the stepwise excavation procedure. However, the need to reopen the cavity has been questioned [9] and the results of this study suggest that this is unnecessary in the teeth of young patients. These results are in agreement with those of three other studies, Mertz-Fairhurst et al. [16] in permanent teeth, Ribeiro et al. [24] and Lula et al. [13] in deciduous teeth.

Cavity sealing after partial removal of carious tissue may modify bacterial growth and drastically reduce the presence of cariogenic bacteria. Moreover, as seen in this study, their persistence does not seem to be a reason for reopening cavities in deciduous and permanent teeth after partial caries removal $[10,13]$. In addition, it does not depend on the type of filling material used $[16,24,25]$ because the aim is to effectively seal the lesion from the oral environment. Although, in this study it was used different pulp treatments according to the group (complete or partial caries removal) and it can be considered a limitation of the study.

The possibility of indicating partial removal of deep carious lesions in a single session, as part of the public service protocol, would bring advantages to the patient and the service. The benefit to the patient would be a more conservative and simultaneously a less invasive approach to caries treatment, reducing widespread anxiety among dental patients [12]. As regards the service, decreasing the treatment from two to one session would be reduce both time and cost, allowing a larger number of patients to be treated, in addition to preventing pulp exposure and probably future need for endodontic treatment. Endodontic treatment should be indicated when all possibilities of less invasive treatment have been exhausted. Hommez et al. [26] demonstrated that when there was good coronal restoration in teeth with good endodontic treatment, $22.5 \%$ of these teeth had apical periodontitis. In the mentioned study, this means that of the 182 endodontically treated teeth, 41 were unsuccessfully treated.

During the vitality tests, one tooth presented painful symptoms after 12 months of the treatment, but the painful sensation ceased immediately after the stimulus was removed. In this case, the first permanent molar was the affected tooth and the patient was twelve years old. The lesion was clinically undetected and could only be diagnosed after the radiographic examination. The lesion was soft and wet, as were the majority of the lesions included in this study. This symptom could be associated with reversible pulpitis. This diagnosis implied that the pulp was vital, but had some areas of inflamed tissue that would heal after conservative vital pulp therapy [27]. Mild trauma with subsequent inflammation can cause small regions of neurogenic inflammation and sufficient mechanical damage to stimulate a nerve sprouting reaction [28] and thereby possibly cause exaggerated response to vitality tests, indicating more severe inflammation than is actually present.
Fifty percent of the teeth treated were clinically undetected lesions; this means that the lesions, in which the enamel was apparently intact, were detected by radiographic examination and not during visual examination. It shows that partial caries removal can be used in both clinically undetected and clinically detected lesions.

Five adolescents presented more than one tooth for assessment, so that they had the chance to be allocated to more than one group in this study, which might represent a limitation, such as the sample size. This sample was drawn from an epidemiologic survey that was carried out in 3 schools in the municipality, and among the school children who was examined; only 20 presented deep caries lesions. It is important to mention that of these, five volunteers presented dentin caries lesions that affected tooth surfaces other than the occlusal surface, or presented established periapical lesions. These volunteers were referred to the Faculty clinic for treatment.

Recent concepts, such as partial carious dentin removal have not yet been adopted in everyday practice [7,8]. Thompson et al. [7] suggested that before this concept be accepted by dental professionals, additional clinical trials would be necessary. Therefore, despite the limitation of being a preliminary study, our results add evidences to previous studies $[13,16,24]$ and provide dental professionals with support to make decisions in caries management.

\section{Conclusion}

Maintenance of pulp vitality is the primary objective of the conservative treatment of deep carious lesions [3]. The results of this study suggest that the partial removal of dentin caries in a single session in permanent teeth could be the elective treatment to attain this objective, since no unsatisfactory clinical and radiograph results were shown for both partial and complete caries removal treatments.

\section{Acknowledgment}

This study was supported by FAPESP (05/59070-1). The funders had no role in study design, data collection and analysis, decision to publish or preparation of the manuscript.

\section{References}

1. Ricketts DN, Pitts NB (2009) Traditional operative treatment options. Monogr Oral Sci 21: 164-173.

2. Hien N (2009) Editorial. J Minim Interv Dent 2: 206

3. Casagrande L, Falster D, Hipólito V, Góes MF, Straffon LH, et al. (2009) Effect of adhesive restorations over incomplete dentin caries removal: 5-year followup study in primary teeth. ASDC J Dent Child 76: 117-122.

4. Featherstone JDB (2008) Dental caries: a dynamic disease process. Aust Dent J 53: 286-291.

5. Ten Cate JM, Featherstone JDB (1996) Physicochemical aspects of fluorideenamel interactions. Fluoride in Dentistry. Copenhagen, Munksgaard.

6. Kidd EA (2004) How "clean" must a cavity be before restoration? Caries Res 38: $305-313$.

7. Thompson V, Craig RG, Curro FA, Green WS, Ship JA (2008) Treatment of deep carious lesions by complete excavation or partial removal. A critical review. J Am Dent Assoc 139: 705-712.

8. Doméjean-Orliaguet S, Léger S, Auclair C, Gerbaud L, Tubert-Jeannin S (2009) Caries management decision: Influence of dentist and patient factors in the provision of dental services. J Dent 37: 827-834.

9. Ricketts DN, Kidd EA, Innes N, Clarkson J (2006) Complete or ultraconservative removal of decayed tissue in unfilled teeth. Cochrane Database of Syst Rev.

10. Oliveira EF, Carminatti G, Fontanella V, Maltz M (2006) The monitoring of deep caries lesions after incomplete dentin caries removal: results after 14-18 months. Clin Oral Investig 10: 134-139.

11. Oen KT, Thompson VP, Vena D, Caufield PW, Curro F, et al. (2007) Attitudes 
Citation: Rando-Meirelles MPM, Tôrres LHN, Sousa MLR (2013) Twenty-Four Months of Follow-up after Partial Removal of Carious Dentin: A Preliminary Study. Dentistry 3: 162. doi:10.4172/2161-1122.1000162

and expectations of treating deep caries: a PEARL Network survey. Gen Dent 55: 197-203.

12. Mickenautsch S (2005) An introduction to minimum intervention dentistry. Singapore Dent J 27: 1-6.

13. Lula EC, Monteiro-Neto V, Alves CM, Ribeiro CC (2009) Microbiological analysis after complete or partial removal of carious dentin in primary teeth: a randomized clinical trial.Caries Res 43: 354-358.

14. Orhan AI, Oz FT, Ozcelik B, Orhan K (2008) A clinical and microbiological comparative study of deep carious lesion treatment in deciduous and young permanent molars. Clin Oral Investig 12: 369-378.

15. Ricketts DN (2008) Deep or partial caries removal: which is best? Evid Based Dent 9: 71-72

16. Mertz-Fairthurst EJ, Curtis Jr. JW, Ergle JW, Rueggeberg FA, Adair SM (1998) Ultraconservative and cariostatic sealed restorations: results at year 10. J Am Dent Assoc 129: 55-66.

17. Falster CA, Araujo FB, Straffon LH, Nör JE (2002) Indirect pulp treatment: in vivo outcomes of an adhesive resin system vs calcium hydroxide for protection of the dentin-pulp complex. Pediatr Dent 24: 241-248.

18. Rando-Meirelles MP, Sousa MLR (2011) Using laser fluorescence (DIAGNOdent) in surveys for the detection of noncavitated occlusal dentine caries. Community Dent Health 28: 17-21.

19. Leksell E, Ridell K, Cvek M, Mejàre I (1996) Pulp exposure after stepwise versus direct complete excavation of deep carious lesions in young posterio permanent teeth. Endod Dent Traumatol 12: 192-196.
20. Bjørdal L, Larsen T, Thystrup A (1997) A clinical and microbiological study of deep carious lesions during stepwise excavation using long treatment intervals. Caries Res 31: 411-417.

21. Bjørdal L, Thylstrup A (1998) A practice-based study on stepwise excavation of deep carious lesions in permanent teeth: a 1-year follow-up study. Community Dent Oral Epidemiol 26: 122-128.

22. Bjørndal L, Larsen T (2000) Changes in the cultivable flora in deep carious lesions following a stepwise excavation procedure. Caries Res 34: 502-508.

23. Maltz M, Oliveira EF, Fontanella V, Bianchi R (2002) A clinical, microbiologic and radiographic study of deep caries lesions after incomplete caries removal. Quintessence Int 33: 151-159.

24. Ribeiro CCC, Baratieri LN, Perdigão J, Baratieri NMM, Ritter AV (1999) A clinical, radiographic, and scanning electron microscopic evaluation of adhesive restorations on carious dentin in primary teeth. Quintessence Int 30: 591-599.

25. Franzon R, Casagrande L, Pinto AS, García-Godoy F, Maltz M, et al. (2007) Clinical and radiographic evaluation of indirect pulp treatment in primary molars: 36 months follow-up. Am J Dent 20: 189-192.

26. Hommez GM, Coppens CR, de Moor RJ (2002) Periapical health related to the quality of coronal restorarions and root fillings. Int Endod J 35: 680-689.

27. Sigurdsson A (2003) Pulpal diagnosis. Endod Topics 5: 12-25

28. Byers MR, Narhi MVO, Mecifi KB (1988) Acute and chronic reactions of dental sensory nerve fibers to cavities and desiccation in rat molars. Anat Rec 221 : 872-883. 